\title{
El concepto de verdad en la Ciencia Jovial. Tensiones en torno al concepto de verdad a partir de la relación entre esta y los espíritus fuertes y débiles en la obra Ciencia Jovial *
}

The concept of truth in The Gay Science. Conceptual tensions in truth regarding its relationship to strong and bound spirits.

\author{
Por: Rueda Pigliacampo, Romelia* \\ Universidad Nacional del Nordeste \\ E-mail: romeliaruedapigliacampo@gmail.com
}

Fecha de recepción: 15/03/2020

Fecha de aprobación:20/04/2020

DOI: $10.30972 /$ ach.054320

\section{Resumen}

Nietzsche critica fuertemente la idea de verdad como un absoluto, pues esta es $r$ refugio de los espíritus débiles quienes esconden detrás de esta verdad objetiva una búsqueda de tranquilidad y acuerdo que en el origen son expresiones de voluntades subjetivas. En contraposición a este grupo se encuentran los espíritus que por su fuerza ponen a prueba toda verdad. . A partir de esta disyunción detectada, pensamos que se presenta una tensión en torno al concepto de verdad en Nietzsche, tensión que este artículo pretende explorar bajo la idea de que si bien la pretendida verdad siempre ha sido una construcción simbólica y como tal una mentira, esto no invalida la existencia de una noción de verdad que desde la tesis del perspectivismo, puede pensarse como una miriada de perspectivas que surgen al interior de una situación determinada.

\footnotetext{
* El presente trabajo surgen en marco de la cátedra Seminario I. Análisis de una obra filosófica del año 2019.

*Estudiantx de la Licenciatura en Filosofía de la Facultad de Humanidades (UNNE).
} 


\title{
Palabras claves
}

Verdad, perspectivismo, conocimiento, espíritus fuertes, pragmatismo

\begin{abstract}
The notion of absolute truth is strongly criticized in Nietzsche's philosophy as the author claims that this aims at producing a sense of conformity and agreement in a specific social group identified as bound spirits, whose weakness motivates them to embrace as objective truth what in reality are social conventions and hidden expressions of subjective wills. While bound spirits hold on to this view, strong spirits are those capable of calling truth into question. This disjunction will help us to explore tensions between different Nietzschean conceptions of truth. The thought behind this article is that although the so-called truth has always been a symbolic construction, and as such a lie, it does not mean that there is no truth, but rather, that, from the thesis of perspectivism, truth can be conceived as multiple perspectives taking place within a given situation.
\end{abstract}

\section{Keywords}

Truth, perspectivity, knowledge, strong spirits, pragmatism

\section{Cómo citar este artículo:}

APA: Rueda Pigliacampo, R. (2020). El concepto de verdad en la Ciencia Jovial. Tensiones en torno al concepto de verdad a partir de la relación entre esta y los espíritus fuertes y débiles en la obra Ciencia Jovial, Acheronta, 5, 114-132. Recuperado de: (agregar dirección web) 
Abril 2020.

\section{Introducción}

La filosofía de Nietzsche, lejos de presentarse como un sistema que pretende cubrir de sentido unidimensional a las cosas, desarrolla la tesis del perspectivismo como posibilidad de alejarse de las solidificación del vínculo entre las denominaciones y los significados que se pretenden en correspondencia total con los objetos de la realidad. La realidad es definida como perspectiva, constantemente cambiante, y no un punto referencial fijo, estático con respecto a algo que está en movimiento; la interpretación es resultante de condiciones de vida propias del sujeto que la realiza, y no algo que se elabora indiferente de la experiencia y que despojada de ella, logre captar la dimensión objetiva de lo real. Existe entonces en esta filosofía de la interpretación una conciencia de la diferencia entre la realidad y el modo en el que se la piensa a partir del lenguaje y la lógica. La realidad que podemos captar es una instancia nominada con palabras y conceptos y no algo existente por fuera del lenguaje y el pensamiento. Dentro del contexto de esta filosofía, la verdad es una interpretación (o construcción) y como tal no puede existir más allá de las perspectivas, ni como el equivalente de todas las perspectivas posibles, puesto que no hay verdades en sí referidas a la realidad, sino interpretaciones de la realidad. Desde la hipótesis gnoseológica del perspectivismo, Nietzsche realiza una crítica a un concepto de verdad entendida como esencia y construye una nueva noción de lo que llamamos verdadero.

El presente trabajo, centrado principalmente en La ciencia Jovial, se propone explorar los significados de verdad e identificar las tensiones que surgen en torno a ella. Específicamente nos concentraremos en indagar qué hay de error, de no verdad en la verdad, y si en Nietzsche existe un gusto por las no verdades, las mascaradas, las apariencias y un consecuente rechazo de la verdad, o si más bien existe un rechazo de estas representaciones ilusorias a partir de una cierta concepción de verdad.

Para tal propósito, nos serviremos de la fuente principal de nuestros comentarios y otros textos del autor en los que se trate el tema de la verdad. Asimismo utilizaremos como bibliografía complementaria el libro "the Shortest Shadow" de Zupancic y un ensayo "L'ultime Scepticisme. la vérité comme régime 
d'interprétation" de Wotling. Partiendo del supuesto de que la verdad funciona como criterio de demarcación de dos grupos en los que Nietzsche entiende que la sociedad se divide: espíritus débiles o de rebaño y espíritus fuertes o superiores, trataremos de dilucidar el valor de la verdad para cada grupo. Para tal fin, en un primer momento, nos proponemos caracterizar y comparar las dos tipologías de espíritu en aquellos aspectos que sirvan para identificar y circunscribir las nociones de verdad a las que suscriben y su relación con el conocimiento, la moral y la religión. La pregunta que articulará nuestra indagación sobre estos valores remite a las necesidades o estados afectivos que se encuentran en el origen de las formas de concebir la verdad para cada espíritu. Esto nos servirá para abordar lo que pensamos son concepciones de verdad cuya relación se nos presenta como problemática.

\section{Delimitación de dos grupos en la sociedad: espíritus fuertes y débiles}

En el aforismo $\$ 2$ de la Ciencia Jovial, Nietzsche reflexiona acerca de la falta de lo que denomina conciencia intelectual. Las característica fundamental de esta carencia es el desinterés por preguntarse por las razones que sostienen creencias, actitud cuyas consecuencia es tomar fácilmente las convenciones como verdades. Nietzsche nos alerta sobre los que no se preguntan sobre las cosas a las que suscriben, pues carecen de conciencia intelectual. " [...] encontrarse en medio de esta rerum concordia discors [armonía disarmónica de las cosas], y de la total y maravillosa incertidumbre y ambigüedad de la existencia, y, pese a eso, no preguntar, no estremecerse ante el deseo y el placer de preguntar, [...] eso es algo que siento como despreciable [...]"

La contracara de esta postura es la de los hombres que señalan la arbitrariedad de las designaciones que circulan en la sociedad. En este sentido, todo individuo que exija en los demás hombres un deseo de poner en cuestión las cosas será visto con ojos extraños e identificado con algo malo. Estos individuos, sin embargo, "buscan razones cuando los otros buscan creencias" (HH §225). Más aún: «Por lo demás, no estriba la esencia del espíritu libre en tener miras más justas, sino solamente en libertarse de lo tradicional, sea con buen o mal éxito. Por lo general, están en la 
Abril 2020.

verdad, el espíritu libre busca razones, los demás buscan una creencia.» En este sentido, en el aforismo 51 describe en qué estriba una búsqueda sincera de razones: "no quiero oír nada de todas esas cosas y preguntas que no aceptan el experimento". La sinceridad, en consecuencia, reside precisamente en no aceptar las verdades que sirven al instinto gregario de los débiles sino en hacer del deseo de certeza "el anhelo más íntimo y más profunda necesidad" (CJ§ 2).

La falta de deseo de interrogantes por parte de un sector de la sociedad, de hacerse consciente de las razones que sustentan o desbaratan las creencias redunda en este grupo en un instinto de conservación de las tradiciones. Sin la acción de preguntarse por lo que se esconde detrás de los absolutos, no se da lugar a la novedad y al crecimiento vital. En estos hombres hay "una restricción que funciona como ley interior haciéndoles decir: "No quiero ver nada que esté en contra del sentido común. ¿Estoy hecho yo para descubrir nuevas verdades? Demasiadas antiguas existen ya" (CJ §25). Los fragmentos antemencionados muestran la resistencia que opone cierto grupo social a la producción de nuevos conocimientos, ya que estos descubrimientos o experimentos como los llama Nietzsche perturbarían las convenciones culturales y morales. En este sentido, cuando un conocimiento nuevo surge, las verdades habituales se ponen en cuestión si este irrumpe en la vida y costumbres de una sociedad. A estas nuevas perspectivas se enfrentan los espíritus gregarios porque consideran la novedad como un desafío a los hábitos establecidos en una cultura (Safranski,2002, p. 241). Por esta razón los débiles o espíritus de rebaño consideran como malos y como peligrosos a los espíritus fuertes o superiores. Estos últimos experimentan libertad de voluntad y autodeterminación, o necesitan certezas, es su propia fuerza la que les posibilita mantener el el equilibrio sobre posibilidades ligeras y cambiantes.

La verdad como criterio de diferenciación entre nobles y débiles

Es posible medir la fuerza de un espíritu en relación a cuánta verdad es capaz de soportar. Nietzsche expone esta tesis en Ecce Homo en el contexto de la búsqueda del 
saber, la necesidad de conocer. Detengámonos a ver a qué llama verdad dentro de este pasaje:

Una prolongada experiencia, proporcionada por ese caminar en lo prohibido, me ha enseñado a contemplar las causas a partir de las cuales se ha moralizado e idealizado hasta ahora, de un modo muy distinto a como tal vez se desea: se me han puesto al descubierto la historia oculta de los filósofos, la psicología de sus grandes nombres. ¿Cuánta verdad soporta, cuánta verdad osa un espíritu? Esto fue convirtiéndose cada vez más, para mí, en la auténtica unidad de medida. El error (el creer en el ideal) no es ceguera, el error es cobardía. Toda conquista, todo paso adelante en el conocimiento es consecuencia del coraje, de la dureza consigo mismo, de la limpieza consigo mismo. (EH§3)

El transitar por todo aquello que se presenta como problemático y prohibido por la moral es el paso hacia adelante en el conocimiento, y en la verdad. En este pasaje la verdad sería lo opuesto a sostener ideales y artículos de fe. Los espíritus débiles son movidos a cometer estos tipos de errores por cobardía, es decir, por un estado afectivo -fisiológico- que tiene un correlato en su actitud para el conocimiento. Los espíritus fuertes son valientes y es ésta característica afectiva la que determina que conquisten nuevos conocimientos.

La fuerza de un espíritu se mide en relación a cuánta verdad puede tolerar. El grado de verdad que soportar se mide en relación a la necesidad que tenga de disfrazar, ficcionalizar la verdad. Nos preguntamos entonces por lo que determina que un espíritu necesite matizar la verdad y si aquello que subyace a la actitud hacia la verdad responde a una necesidad de orden moral o intelectual. 
Abril 2020.

ISSN 2344-9934

\section{Los espíritus débiles: búsqueda de verdades tranquilizadoras}

En los siguientes apartados se expondrán las características de los espíritus débiles hacia la verdad. Estas son: necesidad psicológica de tranquilidad; búsqueda de placer y necesidad de creencias.

Los espíritus débiles se caracterizan por la urgencia psicológica de tranquilidad, la cual lleva a reducir lo desconocido y por tanto inquietante y peligroso- a lo que es familiar. En los débiles de espíritu opera el instinto de eliminar estados angustiantes (CI5). Para ellos "cualquier explicación es mejor que ninguna. Dado que en el fondo se trata solamente de un querer librarse de representaciones que oprimen, no se aplican unos criterios muy rigurosos que digamos a los medios para librarse". De este modo, la primera explicación que sea útil para reducir lo incógnito, lo no experimentado a lo conocido es tenido por verdadero. Nuevamente nos encontramos con la búsqueda de alivio que se hace efectivo por medio de explicaciones reduccionistas. Como resultado se imponen causas aliviadoras para interpretar la realidad desde una única perspectiva. ¿esta obtención de tranquilidad funciona como criterio para fundar una verdad adaptada al tipo de vida de los espíritus más bajos ? Pareciera que las verdades son funcionales a un deseo: desembarazarse de todo lo problemático, no indagar las zonas inexploradas y establecer principios que permitan la autoconservación. En otras palabras, un motivo por el que los espíritus débiles toman como verdadera una única concepción de la realidad es porque le es necesaria para sostener y conservar la sociedad. Chestov $(1949$, p89) apunta que el que intente considerar la vida de otra manera será calificado de anormal, atributo que puede darse a los espíritus fuertes. En esta cuestión todo lo desconocido, problemático es tomado por falso; la contradicciones propias de la lúgubre realidad no son más que mentiras.

Detengámonos en las causas preferidas por los hombres gregarios para eliminar las incógnitas. Nietzsche nos ofrece la siguiente reflexión: “ Lo nuevo, lo no vivenciado, lo ajeno es excluido como causa. Así pues, se busca como causa [...] un tipo de explicaciones escogido y preferido [...] La elección de determinadas explicaciones y no otras se debe a que la interpretación, que también es valoración, surgen del modo de 
ser o de vida de cada uno (Deleuze, 1998, p11). El modo de vida bajo, débil tiene su correlato en la forma de representarse la realidad y se sitúa en las antípodas del modo de vida superior.

Desde la filosofía crítica Nietzscheana, la búsqueda de placer funciona como un criterio de verdad entre los débiles. De la relación entre verdad y placer se sigue que este tipo de hombre cree que las sensaciones agradables, tranquilizadoras necesariamente son garantía de verdad. Tomemos como ejemplo lo expuesto en el aforismo 50 del Anticristo a propósito de la creencia de que la fe hace bienaventurados a los creyentes y por consiguiente es verdadera. Bienaventuraza, denuncia Nietzsche, es placer y este no puede ser prueba de verdad, porque no hay forma de demostrar que los juicios verdaderos son más placenteros que los falsos. La verdad que define requiere transitar un camino de luchas, renuncias y disciplinas pues "servir a la verdad representa el más duro de los servicios; es una verdad que hasta pareciera que fuese peligrosa, y que solo los espíritus fuertes podrían transitar su camino.

En el aforismo 347 de la Ciencia Jovial, Nietzsche dice: “Considérese hasta qué punto alguien necesita creer para crecer; considérese cuánta $<<$ firmeza $>>$ no susceptible de ser sacudida necesita, porque se sostiene en ella: he aquí un criterio para calibrar su grado de fuerza (o dicho más claramente, de su debilidad)."

En la sociedad hay quienes necesitan creer para crecer, supeditan su desarrollo y expansión a la necesidad de creencias, de tener algo firme de modo absoluto e inamovible. Estos anhelos de sostén responden a un instinto de debilidad en el hombre que buscan conservar convicciones que sostienen sistemas tales como religiosos, metafísicos y científicos, pues esta necesidad de apoyo en un suelo firme se manifiesta también en la ciencia. Son los débiles quienes experimentan estos anhelos de estabilidad. Más adelante denuncia que "allí donde más se ha deseado tener fe, donde ha hecho falta con mayor urgencia, faltaba voluntad". La falta de voluntad afirmativa en los hombres se manifiesta por la búsqueda de un amo, algo que encarne el rol de autoridad moral, religiosa, política o gnoseológica. Los débiles son presas de 
Abril 2020.

un hipnotismo intelectual y sensible a aras del fortalecimiento de una única perspectiva que buscarán imponer como interpretación de la realidad.

Encontramos la crítica a la fe como medio de vinculación con la realidad en la metáfora de la ceguera. Hablar de sangre de teólogo indica de que la fe es un fenómeno de origen fisiológico que impulsa a estos hombres a ver falsamente las cosas. "Quien tiene sangre de teólogo en su cuerpo se muestra ya de antemano retorcido y deshonesto frente a la verdad. llama fe al estado afectivo que crece de aquí: cerrar los ojos ante uno mismo de una vez por todas para no tener que sufrir la visión de una falsedad incurable." (AC §9). La perspectiva falseada que proyecta la fe busca satisfacer intereses pulsionales. En el mismo aforismo dice: "Lo que un teólogo siente como verdadero tiene que ser falso necesariamente: he aquí casi un criterio de verdad. Es su más profundo instinto de conservación el que le impide honrar la realidad [...]" (AC §9). Este tipo solo siente la verdad, y para Nietzsche esta verdad tiene que ser una falsedad puesto que en razón de una organización pulsional desequilibrada se rechaza la realidad. Esta "verdad" es el idealismo como ceguera que escamotea la realidad. "Todo lo que hasta ahora se llamó «verdad» ha sido reconocido como la forma más nociva, más pérfida, más subterránea de la mentira" (EH, IV, § 8).

\section{Los hombres superiores: una forma original de escepticismo}

La independencia de las verdades tiranizantes es lo que caracteriza a los hombres superiores. Estos están en guardia frente a las apresuradas adhesiones a convicciones y artículos de fe, tantos las que afirman la validez imbatible de ciertos juicios, como la negación de otros tipos de juicios en contradicción con los afirmados. La actitud que posibilita el cuestionamiento radical es una que Nietzsche llama epicúrea: curiosidad ante lo enigmático, gusto por lo problemático y un cierto escepticismo manifiesto en la prudencia ante las convicciones, que Nietzsche asocia a la imagen del jinete y su habilidad en "mantener tirantes las riendas ante nuestro ímpetu lanzado hacia adelante en busca de la certeza, este autodominio del jinete en su cabalgata más salvaje" (CJ §375). 
Los hombres superior plantean interrogantes a todo lo que ha sido considerado solemne, de incuestionable veracidad y bondad como la moral, la ciencia y la religión. "un espíritu para quien lo supremo donde el pueblo sitúa con justicia su criterio de valor, no significaría ya más que peligro, decadencia, rebajamiento o, por lo menos, descanso, ceguera, olvido temporal de sí mismo" (CJ§ 382). Los superiores, desde su desbordante plenitud se preguntan por lo que se esconde detrás de las convenciones y absolutos, de manera tal que se pueda dar lugar a la novedad y al crecimiento vital. La visión de un espacio no antes explorado, poblado de incógnitas "tan excesivamente rico en cosas bellas,extrañas, problemáticas, terribles y divinas" presupone una actitud de sospecha, de placer ante el carácter incierto de la realidad. Aunque los enigmas crezcan proporcionalmente a su curiosidad, acepta que la realidad excede al hombre; lo inasible de lo real no lo asusta sino que dotados de pasión y amor por los problemas, se aproxima a lo problemático y novedoso novedades con regocijo. "A medida que aumenta la agudeza de su percepción intelectual y la amplitud de su perspicacia, el hombre ve ensancharse ante él el espacio y el horizonte. Su universo se hace más profundo, nuevas estrellas, enigmas e imágenes nuevas aparecen incesantemente a su vista." (MBM§ 57). En contraposición a esto se encuentra la adhesión ciega a lo que hay de sagrado, tan impermeable a la duda que pareciera excluir toda posibilidad de cuestionamiento; en ella estriba la privación de aquella mirada que precisamente ve más allá, privación característica de los espíritus más bajos.

Una consecuencia de la actitud epicúrea hacia el conocimiento, es plantearse el problema de si es posible que existan perspectivas diferentes a las de uno. Captar que "el mundo se ha vuelto, una vez más, >infiniti>> para nosotros, en la medida en que no podemos soslayar por más tiempo a posibilidad de que él contenga dentro de sí infinitas interpretaciones. "(CJ§ 474). Desde esta perspectiva la realidad se identifica como un conjunto de procesos interpretativos variados, y son los hombres superiores quienes tienen la valentía y autodeterminación requeridas para hacer frente sin temor a la indeterminación, la deriva interpretativa de la realidad cambiante. Aproximarse a la realidad concebida de tal forma es una empresa difícil considerando que al haberse cuestionado las categorías morales que antes servían de referencia, el 
Abril 2020.

hombre se encuentra sin estas viejas marcas de orientación, y guiado por un instinto creador (Wotling, 2006 p. 491), producen nuevos valores, nuevas formas que recubren la amalgama de la realidad: " a él como creador, a decir verdad, le es propia la vis contemplativa y la mirada hacia su obra, pero, asimismo, y sobre todo, también la vis creativa. Nosotros los que pensamos y sentimos, somos los que realmente hacemos continuamente algo que aún no está allí: todo el eterno mundo en crecimiento de apreciaciones, colores, pesos, perspectivas, escalas, afirmaciones y negaciones." (CJ§ 301).

Nietzsche describe la actividad creadora de los fuertes como semejante a la de los artistas. Interpretar es deformar siguiendo determinadas lógicas que responden a la imposibilidad de acceder a la realidad sin mediación alguna, sin recurrir a "un montaje de representaciones" (diferentes grados de apariencias) (Zupančič, p100). Los artistas- vis creadora de los fuertes- se distancian de las "cosas hasta el punto de dejar de ver lo que ellas tienen de suyo y así tener que añadir mucho al mirarlas, para seguir viéndolas. o acaso ver las cosas desde un determinado ángulo o fragmentadas; o colocarlas de tal manera que se desfiguren parcialmente y sólo permitan ser contempladas en perspectiva" (CJ§ 299).

Esta faceta creadora se manifiesta como potenciadora de la vida. Deleuze (1998, p 145) explica que la actividad vital consiste en el engaño, mascarada y disimulo. Esta se ve potenciada por la actividad creadora del artista, quien impulsado por una voluntad de engañar, inventa, forja mentiras que son afirmativas como la realidad. El artista abraza el mundo de la apariencia, se aparta de la interpretación del tipo débil que ve en la apariencia la negación del "mundo real".

El mundo por naturaleza es neutral, siendo las asignaciones de valores creadas por hombres condicionados por factores afectivos e históricos y que adhieren a un sistema de valores coherentes con la necesidad de conservar su especie. "todo lo que tiene valor en el mundo actual, no lo tiene en sí mismo, según su naturaleza - la naturaleza siempre carece de valor-, sino que alguna vez se le ha dado, regalado un valor [...]"(C J301). Más aún, califica de falsa y mentirosa este tipo de interpretación, 
que sin embargo está en consonancia con "con nuestros deseos y voluntad de veneración, es decir de acuerdo con una situación de necesidad.". ¿Nos encontramos ante una crítica de la valoración del mundo como asignaciones arbitrarias de sentidos, o ante una crítica a un determinada constelación valorativa?. Los hombres superiores dotados de la capacidad de escuchar y ver más allá, reconocen el proceso de invención y adjudicación de valores a algo que en sí es neutral, pero no lo abaten, si no que comprenden que solo la lectura de un mundo divinizado o "verdadero" es nociva para la vida . "[...] hoy nos hace reír que el hombre pretenda inventar valores que deban exceder el valor del mundo real" (CJ §346). El ideal es lo que los fuertes cuestionan en tanto que aquel se opone al carácter cambiante de la realidad. "El «mundo verdadero» y el «mundo aparente»; dicho con claridad: el mundo fingido y la realidad. Hasta ahora la mentira del ideal ha constituido la maldición contra la realidad, la humanidad misma ha sido engañada y falseada por tal mentira hasta en sus instintos más básicos hasta llegar a adorar los valores inversos de aquellos solos que habrían garantizado el florecimiento, el futuro, el elevado derecho al futuro" (EH§2).

\section{Tensiones en torno al concepto de verdad}

En Nietzsche hay desinterés por la verdad vista como un fin en sí misma, pero vemos que realiza una crítica a la absolutización de la verdad como una actitud de debilidad, cobardía en nombre de una verdad. Si identifica la búsqueda de creencia y convicción -ilusión y mentiras tranquilizadoras- detrás de la búsqueda de verdad por parte de los débiles, la crítica se efectúa a partir de una noción de verdad que no es la misma de aquella verdad elogiada.

\section{Crítica del idealismo: necesidad metafísica}

El idealismo consiste en preferir una idea falsa del mundo (inteligible, moral, religioso) a la del mundo de la vida que es trágico, cambiante y problemático. Este rechazo a la vida lleva a ensalzar lo opuesto a los valores que estimulan y fortalecen la vida, mientras que " a la realidad se la ha despojado de su valor, de su sentido, de su veracidad[...]" 
Abril 2020.

ISSN 2344-9934

La verdad como criterio de valor de un espíritu

El valor de un espíritu se distingue por su capacidad de tolerar la verdad. Esta concepción de verdad está en relación con la necesidad de matizar, diluir la verdad. "[...]la fortaleza de un espíritu se mediría justamente por la cantidad de «verdad» que soportase 0 , dicho con más claridad, por el grado en que necesitase que la verdad quedase diluida, encubierta, edulcorada, amortiguada, falseada" (MBM §39)

La pregunta es ¿a qué concepción de verdad refiere Nietzsche tal que a) le permite criticar a partir de ella al ideal, y b) argumentar que la naturaleza de esta verdad provoca la necesidad de matizarla, para, si se quiere, poder tratar con ella? Para intentar delinear de qué verdad estamos hablando, citamos el siguiente pasaje donde expone aquello que contribuye a la conservación de la vida a pesar de ser falso:

\section{Lo falso no es una objeción}

El hecho de que un juicio sea falso no constituye, en nuestra opinión, una objeción contra ese juicio. Quizá sea ésta una de las afirmaciones más sorprendentes de nuestro nuevo lenguaje. Se trata de saber en qué medida este juicio sirve para acelerar y mantener la vida, para conservar la especie, para mejorarla incluso.. [...] Admitir que no lo verdadero es la condición de vida, es evidentemente oponerse de modo peligroso al sentimiento que se tiene habitualmente de los valores, y una filosofía que se permita tal audacia se coloca, por este solo hecho, más allá del bien y del mal. (MBM I §4)

Por un lado Nietzsche reconoce que las no verdades- cuya falsedad no es una objeción para invalidarlas- son positivas a la expansión vital y inherentes a la posibilidad de vivir. Así, la ilusión, la mascarada, las no verdades serían necesarias para conservarse. Por otro lado, la verdad desde la que se realiza el cuestionamiento de los ideales y se mide el valor de un espíritu, no parece ser la misma que la del pasajes 
citado. En este sentido, Zupančič $(2003)^{1}$ identifica dos líneas argumentativas en Nietzsche respecto a la verdad. Por un lado, esta significa una lucha contra prejuicios, verdades aceptadas, y falsas verdades. Esta verdad pura se identificaría con lo Real, como aquello que va más allá de la posibilidad de percepción y del conocimiento y es antagónica a la vida puesto que no contribuye a la expansión vital, siendo más dañina que benéfica (p. 91) Por otra parte, Nietzsche reconoce el hecho de que las deformaciones propias de la percepción son condiciones para la vida. Uno no puede vivir en la verdad identificada con lo real, aquello que se resiste a lo simbólico, necesita de no verdades, de las construcciones ficticias (lógica de la racionalidad, juicios a priori, valores, concepto de causa y efecto, etc.) para poder actuar. En efecto estamos ante una noción de verdad cuya violencia la hace inasible y por tanto, dadas la incompatibilidad con nuestras fuerzas, nos vemos compelidos a velar o disfrazar.

Zupančič (2003) señala que la tesis común a los argumentos antes mencionados es que la mentira es lo que se llama verdad. En la primera perspectiva, Nietzsche insiste en que lo que se ha llamado verdad hasta entonces debe dejar de serlo, porque la verdad está en otra parte y es la que hasta ahora nos ha estado prohibida (p. 93). Esta verdad es contraria a la vida, ir en pos de ella podría resultar en nuestra aniquilación "Algo podría ser verdadero: aunque resultase perjudicial y peligroso en grado sumo; podría incluso ocurrir que el que nosotros perezcamos a causa de nuestro conocimiento total” (MBM §39) En la segunda interpretación, reconoce que la mentira tomada por verdad es condición de y contribuye a la vida. La verdad entonces significa mentira en tanto es una construcción simbólica. Desde esta perspectiva, la verdad identificada con el error puede asociarse a la realidad en tanto conjunto de procesos interpretativos en donde "no hay lugar para la comprensión de la verdad como un referente absoluto o norma invariante" (Wotling 2001, p. 53). El ser consciente de las no verdades indica que no hay ninguna fetichización de la verdad, contrariamente a la posición que le incumbe a los más débiles, aquella que revela pasión por la verdad.

\footnotetext{
${ }^{1}$ Zupančič realiza un análisis de las concepciones de verdad en Nietzsche sirviéndose de los registros Simbólico -entendido como aquello que es producto de la representación- y Real- aquello que se encuentra más allá de la simbolización y que se diferencia de la realidad, siendo esta última una construcción simbólica.
} 
Abril 2020.

ISSN 2344-9934

En Nietzsche se dan dos posiciones cuya simultaneidad se nos presenta como una tensión. Por un lado, elogio de las no verdades -ilusiones-, pero por otro, crítica de la necesidad de ilusión como autoengaño y cobardía.

"Suponiendo que nosotros queramos la verdad: ¿porqué no, más bien, la noverdad? ¿Y la incertidumbre? ¿Y aun la ignorancia?” (MBM§1)

"No hay más mundo que el «aparente»: el «mundo verdadero» no es más que un añadido falaz." (Cl, la razón en la Filosofía, 2)

"Las razones por las que se ha considerado que «este» mundo es aparente constituyen más bien el fundamento de su realidad; cualquier otra forma de realidad resulta totalmente indemostrable." ( $\mathrm{Cl}$, idem 6).

Si la verdad es un valor que resulta de fijación de preferencias que se traducen en una determinada interpretación de la realidad, la determinación de la diferencia entre el elogio y el cuestionamiento de la verdad como ilusión requiere identificar las necesidades que buscan satisfacerse en la verdad como interpretación de la realidad.

Nietzsche realiza una crítica a todo lo que tenga origen en una organización pulsional desequilibrada que identifica con la debilidad. Estas orientan una búsqueda de verdades-ilusiones que reconforten y conserven un tipo de vida que no es afirmativa. Son mentiras nocivas, en contra de todo lo que hay de bueno en la vida.

Deleuze (1998) advierte que en la crítica nietzscheana de la verdad hay que preguntarse no por las falsas pretensiones de verdad, sino por la verdad como ideal y la voluntad que subyace a este ideal. El énfasis de la reflexión se sitúa en torno a quiénes son los que buscan la verdad así entendida, qué quieren con ella, cuál es su voluntad de poder. Existe así un hombre verídico que sostiene un concepto de verdad que se corresponde a la representación de un mundo verídico y su voluntad es la de no dejarse engañar. Detrás de esta voluntad se halla la creencia de que "ser engañado es algo perjudicial, peligroso, funesto" (CJ §344). El peligro de este tipo es que contrapone una concepción de mundo que en realidad no es, a un mundo que es ( un 
mundo de apariencias, de engaño y disimulo) y de este modo deprecia la vida, y lo ficcional propio de la vida. El que anhela otro mundo y otra vida quiere « La vida contra la vida», quiere que la vida se haga virtuosa, que se corrija y corrija la apariencia, que sirva de paso al mundo verídico. Quiere que la vida reniegue de sí misma y se vuelva contra sí misma (Deleuze,1998). El hombre verídico reniega de la vida porque prefiere una vida degradada, disminuida, y busca la conservación de su tipo.

En los débiles, su interpretación de la realidad cuya lógica no responde a una búsqueda gnoseológica sino moral hace a la expansión y conservación de su tipo de vida. En los apartados anteriores hemos expuesto el rechazo de la realidad aparente, percibida como peligrosa por aquellos que disponiendo de escasos recursos para domeñar la realidad cambiante, despliegan estrategias de compensación de su debilidad, como ser los artículos de fé, el ideal, la inversión de valores (lo bueno es lo "malo", lo que vuelve enfermo es bueno, lo que procede de la abundancia es malvado). Trataremos de ilustrar la crítica al origen débil de esta noción de verdad a partir de la figura del filósofo. En el segundo apartado del prefacio a la Ciencia Jovial, Nietzsche nos presenta al filósofo que piensa a partir de la carencia y necesidad espiritual conjeturando que esta versión de pensador enfermo es la que ha abundado en la historia de la filosofía. El pensamiento conformado bajo "la presión de la enfermedad" incita la búsqueda de "[ ...] sol, la quietud, la suavidad, la paciencia, la terapia, el alivio en cualquier sentido". Su pensamiento, contrariamente a lo que creen, no es producto objetivo de un espíritu fuerte, sino que es relativo, deseante de ilusiones tranquilizantes. Queda en evidencia entonces el intento de esconder las necesidades, las faltas espirituales y corporales bajo el disfraz de "lo objetivo, ideal, puramente espiritual". No hay motivos para pensar que la verdad ${ }^{2}$ que profesan escapa a esta lógica, pues funciona como una ilusión interpretativa eficaz para un tipo de vida.

\footnotetext{
2 La idealización de la verdad lleva a una paradoja. En el caso de los filósofos, estos se afanan por cubrir el origen pulsional de las verdades que sostienen bajo el disfraz del ideal. Si esta verdad se presenta como algo divino, queda exenta de la interrogación de la razón. En este sentido Wotling (2006) señala la contradicción de la idea de verdad: exige de todo enunciado que pueda ser tomado por cierto su previa demostración por medio de la razón, pero ella nunca se somete a dicho escrutinio.
} 
Abril 2020.

ISSN 2344-9934

Las no verdades celebradas por los espíritus fuertes son ilusiones, pero estos tienen consciencia de lo irreductible de la realidad en el sentido de que comprenden que no puede ser reducida a valores absolutos que se erijan como única interpretación válida y absoluta de la misma. Reconocen entonces que hay múltiples formas de acercarse a la realidad, siendo los valores, entre ellos la verdad, la traducción de determinadas interpretaciones contextualizadas. La verdad es entonces no-verdad forjada en determinadas coordenadas culturales, sociales y epocales, es inmanente a la una configuración particular fuera de la cual no podría existir. Esto no quiere decir que exista una correspondencia entre situación y una sola verdad o perspectiva, puesto que en una configuración pueden formularse diversas perspectivas siendo imposible salirse de la situación y proponer una verdad eminente. Se trata de determinar la vitalidad de los valores preguntándose si son útiles o no a la vida. La verdad es un valor, una invención útil relativa al individuo o grupo que la sostenga, de allí que sea imposible hablar de verdades absolutas y universales aplicables a la realidad. Al hablar de las características afirmativas y útiles de la verdad podemos pensar que se trata de una lectura pragmática. La verdad es una interpretación entre otras posibles que surgen como respuesta a la demanda de un tipo de vida que está en relación con deseos y necesidades particulares, de este modo, las condiciones de verdad dependen de las acciones que se despliegan en determinadas situaciones.

Los débiles creen que las ficciones que manejan son verdades absolutas mediante cuales alcanzan una lectura verdadera de lo que es la realidad. Las verdades se conciben como una axiología que guía sus acciones y como leyes naturales estáticas que sirven para fijar el constante devenir de la realidad. Logran así preservarse de un mundo de cara al cual carecen de recursos para soportar. Lo que distingue a los fuertes de los débiles es ese recurso que podemos definir como la conciencia intelectual de que la verdad es una no verdad, de que es un valor y no una esencia y sin embargo, soportan vivir en un mundo interpretado desde la pantalla ficticia de las verdades, sin nunca traspasar los límites de lo Real o la realidad en sí. Las verdades son ilusiones y con ellas " no llegamos a tocar la esencia del mundo es sí" (Safranski, 2002, p. 161). 


\section{Conclusión}

En esta instancia final nos proponemos verificar si hemos cumplido con los objetivos enunciados y dar cuenta de las respuestas tentativas a la problemática planteada. Nietzsche critica fuertemente la idea de verdad como un absoluto. Observa que hay tipos humanos que adscriben a esta concepción tiranizante de verdad en contraposición a otros que se embarcan en la tarea de desmantelarla. A los primeros, en razón de su actitud, los llama espíritus débiles o de rebaño. En oposición a ellos se encuentran los espíritus fuertes o superiores, predispuestos a poner a prueba toda verdad. En esa contraposición, los espíritus débiles o de rebaño arrastran el problema de la verdad al terreno moral y tratan de resolverlo con convenciones que permitan fijar valores universales y absolutos aplicables a la realidad. Sin embargo, los espíritus fuertes plantean la problemática de la verdad fuera de ese terreno, ya que, como Nietzsche lo reconoce, se trata de limitaciones que remiten a necesidades morales y psicológicas que a su vez traducen el problema de falta de conciencia intelectual, carencia que lleva a los hombres del rebaño a tomar como ciertas las convenciones que se imponen en el tiempo. Los espíritus fuertes se emancipan a partir de la experiencia de duda, de sospecha hacia todo lo impuesto por convención como la única lectura posible de la realidad que se cristaliza en los conceptos incuestionables como los de verdad, bondad y realidad. La sospecha lleva a rechazar el sistema axiológico fijado por acuerdo y sostenido en el tiempo en pos de crear nuevos valores que lejos de buscar alcanzar el estatus de norma absoluta de se un "en sí" universal, se presenten como construcciones provisorias situadas que, originados desde la abundancia de fuerzas, sean útiles para desenvolverse en una realidad del devenir y la transformación.

El mundo, la realidad en sí son inaccesibles al conocimiento, son un punto indeterminado desde el cual podemos considerar que las perspectivas son posibles acercamientos entre muchos otros que se construyen desde posiciones determinadas con arreglo a la utilidad que puedan prestar a un tipo de vida. Las perspectivas como 
Abril 2020.

ISSN 2344-9934

lecturas de la realidad representan el conocimiento recortado y situado que tenemos de ella, limitación que es asumida y celebrada por los espíritus fuertes que no pretenden esconder el origen circunstanciado y creado de las cosas bajo una pretendida universalidad. Ante la pregunta de si la crítica apunta a de la valoración del mundo como asignaciones arbitrarias de sentidos, o si,más bien, ante una crítica a un determinada constelación valorativa podemos decir que se trata más bien de lo segundo. Los fuertes no se sitúan por fuera de construcciones axiológicas, puesto que ante la tarea de reevaluar los valores tradicionales, es decir, aquellos que se encuentran fijados por largos periodos de tiempo en el ser de la cultura como el sistema de valores cristianos, los fuertes despliegan su potencial de creatividad para establecer nuevos valores.

Nietzsche propone una noción de verdad que supere la ilusión de verdad absoluta tan anhelada por los hombres del rebaño. Esta verdad se representa como relativa, pero sin caer en un relativismo que habilitaría una indeterminación en la verdad, si no que decir que la verdad es relativa quiere decir que es una verdad en relación a uno mismo, a la contingencia del estar situado en un espacio y tiempo. La imposición de una sola verdad resulta de un trasfondo dogmático que se oculta bajo aparente objetividad. Un espíritu libre se aparta del camino predeterminado trazado para muchos, se distingue por soportar la inestabilidad, la transformación, el estar de paso entre diferentes regiones del espíritu ${ }^{3}$. Su ligereza no requiere del suelo firme $e$ inamovible de las certezas axiológicas y religiosas.

\footnotetext{
${ }^{3} \mathrm{MBM} \S 43$
} 


\section{Bibliografía}

- Chestov, L. (1949) La filosofía de la tragedia. (D.J., Vogelman, Trad.) Buenos Aires: Emecé Editores.

- Deleuze, G. (1998) Nietzsche y la filosofía. (C., Artal, Trad.) Barcelona: Editorial Anagrama.

- Niemeyer, C. (2012) Diccionario Nietzsche: Conceptos, Obras, influencias, lugares. (I., de los Ríos, S. Santana, J.L. Puertas y J. Planells, Trad.) Madrid: Editorial biblioteca nueva.

- Nietzsche, F. (1986). Humano, demasiado humano. (J., Gonzales, Trad.) Ciudad de México: Editores mexicanos unidos.

- Nietzsche, F. (2014a) El Anticristo. (G., Cano, Trad.)Madrid: Gredos

- Nietzsche, F. (2014b) El crepúsculo de los Ídolos. (J., Mardomingo Sierra, Trad.) Madrid: Gredos

- Nietzsche, F. (2014c) La ciencia Jovial. (G, Cano, Trad.) Madrid, España. Gredos.

- Nietzsche, F. (2014d) Más allá del Bien y del Mal. (C., Vergara, Trad.) Madrid: Gredos.

- Safranski, R. (2002) Nietzsche. A philosophical biography. London: Granta Books.

- Wotling, P. (2001) Le vocabulaire de Nietzsche. Paris: Ellipses.

- Wotling, P. (2006) L'ultime Scepticisme. la vérité comme régime d'interprétation. Presses Universitaires de France. Revue philosophique de la France et de l'étranger. no 4/2006, p. 479 à p. 496. Retirado de: https://www.cairn.info/revue-philosophique-2006-4-page-479.htm

- Zupančič, A. 2003. The Shortest shadow-Nietzsche's philosophy of the two. Cambridge, Massachusetts: The MIT Press. 